\title{
Trajetória acadêmica e profissional dos egressos do curso de Medicina Veterinária
}

\author{
Academic and professional trajectory of Veterinary Medicine graduates \\ Trayectoria académica y professional de los graduados de Medicina Veterinaria
}

Recebido: 11/01/2022 | Revisado: 15/01/2022 | Aceito: 24/01/2022 | Publicado: 26/01/2022

\author{
Sonia Mara Fontes dos Santos \\ ORCID: https://orcid.org/0000-0002-3056-9850 \\ Universidade Federal da Fronteira Sul, Brasil \\ E-mail: soniamarafontes31@gmail.com \\ Pâmela Strapasson \\ ORCID: https://orcid.org/0000-0002-9231-4802 \\ Universidade Federal da Fronteira Sul, Brasil \\ E-mail: pamelastrapasson@hotmail.com \\ Karina Ramirez Starikoff \\ ORCID: https://orcid.org/0000-0001-8378-9972 \\ Universidade Federal da Fronteira Sul, Brasil \\ E-mail: karina.starikoff@uffs.edu.br
}

\begin{abstract}
Resumo
Diversos fatores podem influenciar o percurso acadêmico e as consequências refletem no êxito ou nos desafios impostos pela realidade pós formação e no mercado de trabalho. O objetivo desta pesquisa foi analisar a trajetória acadêmica e profissional dos egressos do curso de medicina veterinária da Universidade Federal da Fronteira Sul - UFFS, Campus Realeza/PR. A pesquisa foi realizada por meio da aplicação de questionário, de forma online, com questões sobre as atividades e habilidades desenvolvidas durante a graduação e que impactaram na vida pessoal e profissional, áreas de interesse ao ingressar e se mudou de ideia no transcorrer do tempo, questões sobre a trajetória profissional e exigências do mercado de trabalho, além de atividades não desenvolvidas na graduação e que fariam diferença na rotina profissional. Participaram desta pesquisa um total de 80 egressos, o que representa 43,5\% dos alunos formados. Os resultados demonstraram que mais da metade dos estudantes reprovaram em pelo menos dois componentes curriculares e que os motivos que contribuíram para a retenção foram principalmente dificuldade de adaptação ao modelo de ensino superior, problemas psicológicos e distância da família. Quase metade dos estudantes mudou a área de interesse inicial, pela oportunidade de conhecer outras áreas, mas também em função da demanda de empregos. Entretanto, muitas dificuldades relacionadas às habilidades pessoais foram identificadas após a formação, confirmando a importância de desenvolver não somente o conhecimento técnico, mas outras habilidades importantes exigidas pelo mercado de trabalho.
\end{abstract}

Palavras-chave: Ensino superior; Mercado de trabalho; Habilidades pessoais; Graduação.

\begin{abstract}
Several factors can influence the academic path and the consequences reflect on the success or challenges imposed by the post-graduate reality and in the job market. The objective of this research was to analyze the academic and professional trajectory of the graduates of the veterinary medicine course at Federal University of Fronteira Sul - UFFS, Campus Realeza/PR. The research was made with the application of a questionnaire, online, with questions about the activities and skills developed during graduation and that impacted on personal and professional life, areas of interest when joined and if they changed the choice area, questions about the professional trajectory and demands of the job market, in addition to activities not developed at graduation and that would make a difference in the professional routine. A total of 80 graduates of the veterinary medicine course at UFFS participated in this research, which represents $43.5 \%$ of graduate students. The results showed that more than half of the students failed at least two curricular components and that the reasons that contributed to the retention were mainly difficulty in adapting to the higher education model, psychological problems, and distance from the family. Almost half of the students changed their initial area of interest, due to the opportunity to get to know other areas, but also depending on the demand for jobs. However, many difficulties related to personal skills were identified after training, confirming the importance of developing not only technical knowledge, but other important skills required by the job market.
\end{abstract}

Keywords: University education; Job market; Soft skills; University graduate.

\section{Resumen}

Varios factores pueden influir en la trayectoria académica y las consecuencias se reflejan en el éxito o desafíos que impone la realidad posgraduada y en el mercado laboral. El objetivo de esta investigación fue analizar la trayectoria académica y profesional de los egresados de la carrera de medicina veterinaria de la Universidad Federal de Fronteira 
Sur - UFFS, Campus Realeza/PR. La investigación se realizó a través de la aplicación de un cuestionario, en línea, con preguntas sobre las actividades y habilidades desarrolladas durante la graduación y que impactaron en la vida personal y profesional, áreas de interés al ingresar y si cambiaron de opinión con el tiempo, preguntas sobre las trayectoria profesional y demandas del mercado de trabajo, además de actividades no desarrolladas al egresar y que marcarían la diferencia en el cotidiano profesional. Un total de 80 graduados participaron en esta investigación, lo que representa el 43,5\% de los graduados. Los resultados mostraron que más de la mitad de los estudiantes reprobaron al menos dos componentes curriculares y que las razones que contribuyeron a la retención fueron principalmente la dificultad de adaptación al modelo de educación superior, los problemas psicológicos y la distancia de la familia. Casi la mitad de los estudiantes cambiaron su área de interés inicial, por la oportunidad de conocer otras áreas, pero también por la demanda del trabajo. Sin embargo, se identificaron muchas dificultades relacionadas con las habilidades personales después de la capacitación, lo que confirma la importancia de desarrollar no solo conocimientos técnicos, sino otras habilidades importantes que requiere el mercado laboral.

Palabras clave: Enseñanza superior; Mercado de trabajo; Habilidades personales; Graduado universitario.

\section{Introdução}

A Medicina Veterinária vem sofrendo intensos remodelamentos resultantes de inovações tecnológicas, integração de novas áreas de atuação e exigências sociais, obtendo o reconhecimento do profissional para a área da saúde, com perfil generalista, qualificado e apto a atuar em áreas distintas conforme demanda do mercado profissional (Brasil, 2019).

Em 2012, a Organização Mundial de Saúde Animal (OIE) sugeriu uma lista de competências mínimas necessárias para a formação dos médicos veterinários pelo mundo. O documento prepara o recém-formado para o chamado "Dia 01 ”, ou seja, seu primeiro dia de atuação como profissional. Os veterinários recém graduados deverão dominar as competências básicas propostas como: conhecimento (habilidades cognitivas, capacidades mentais), habilidades (destreza para realizar tarefas específicas); atitudes (capacidade afetiva, referindo-se a sentimentos e emoções) e aptidões (habilidades naturais, talento e capacidade de aprendizagem do estudante). Dessa forma, a OIE espera que ele se torne um profissional mais preparado e completo, que poderá oferecer um trabalho de qualidade à sociedade (OIE, 2012).

O mercado de trabalho para o médico veterinário é promissor e abrangente, e com diversas áreas de atuação como em hospitais veterinários e clínicas, pet shops, frigoríficos, inspeção e tecnologia de alimentos, indústrias, criadouros, reprodução e produção animal, pesquisa, desenvolvimento e agronegócio, laboratórios biotecnológicos e clínicos, biotérios, áreas de proteção ambiental, zoológicos, saúde pública, docência, dentre outros. Ainda, analisando os números da profissão, de 2017 para 2020 , a quantidade de médicos veterinários inscritos no Conselho Federal de Medicina Veterinária (CFMV) aumentou de 111,2 mil para 145,6 mil, um crescimento de 34,3 mil de profissionais em três anos, o que mostra a crescente procura e consequente formação de médicos veterinários no Brasil (CFMV, 2020).

De acordo com Sherman (2010), além de serem os únicos profissionais de saúde cuja formação é baseada na medicina comparativa, com estudos aprofundados na saúde e doença de múltiplas espécies ao longo da ampla variedade taxonômica, médicos veterinários também são treinados para a saúde populacional por atuarem na produção animal e por serem rotineiramente inseridos em questões ambientais e problemas de saúde animal, analisando a qualidade da água, dos alimentos e do ar, para um diagnóstico apropriado.

Ao considerar que informações quanto às expectativas, posturas e valores dos alunos são importantes para direcionar mudanças nos cursos de ensino superior, o objetivo desta pesquisa foi analisar a trajetória acadêmica e profissional dos egressos do curso de medicina veterinária da Universidade Federal da Fronteira Sul (UFFS), Campus Realeza/PR.

\section{Metodologia}

A pesquisa foi realizada após a aprovação pela Comissão de Ética em Pesquisa da UFFS (número 59380516.9.0000.5564). Os registros com nomes e e-mail dos egressos foram disponibilizados pela secretaria acadêmica e o questionário foi aplicado de forma online (Google Forms), e também após permissão dos voluntários por meio do Termo de 
Consentimento Livre e Esclarecido digital, para os formados no curso de medicina veterinária no período de maio a junho de 2021.

Trata-se de uma pesquisa aplicada, descritiva, com base em uma abordagem qualitativa e quantitativa. A amostra, definida por conveniência, foi composta até obter porcentagem mínima de $40 \%$ de participação dos alunos registrados no sistema institucional (Pereira et al., 2018). Como critérios de inclusão foram utilizadas as respostas dos formados no curso de medicina veterinária na instituição desde a criação (2010) até junho de 2021. Foram excluídos os formados em outros cursos, graduandos e os desistentes.

O questionário foi composto por duas seções:

1. Questões sobre a trajetória do aluno durante a graduação: ano de ingresso e ano de formação, reprovações e dificuldades enfrentadas durante a graduação, realização de estágios e cursos extracurriculares (períodos, duração, em que áreas e locais), atividades e habilidades desenvolvidas durante a graduação e que impactam na vida pessoal e profissional, áreas de interesse ao ingressar e se mudou de ideia com o transcorrer do tempo, estágio obrigatório (local e área);

2. Questões sobre a trajetória profissional: empregos (cargo, duração, regime, local), exigências do mercado de trabalho, cursos de aperfeiçoamento e especializações (residência, pós-graduação, mestrado, doutorado), atividades não desenvolvidas na graduação e que fariam diferença na rotina profissional.

Para análise dos resultados foi utilizado o programa Microsoft Excel® 2011 para cálculo das porcentagens e confecção dos gráficos. Os dados foram analisados através de estatística descritiva (valores mínimos; máximos; médios).

\section{Resultados e Discussão}

Participaram desta pesquisa 80 egressos, sendo 37 homens e 43 mulheres, o que representa $43,5 \%$ dos alunos formados. $\mathrm{O}$ ano de ingresso e o de conclusão dos participantes podem ser observados na Figura 1.

Figura 1 - Ano de ingresso e de conclusão dos egressos participantes desta pesquisa no curso de medicina veterinária da Universidade Federal da Fronteira Sul.

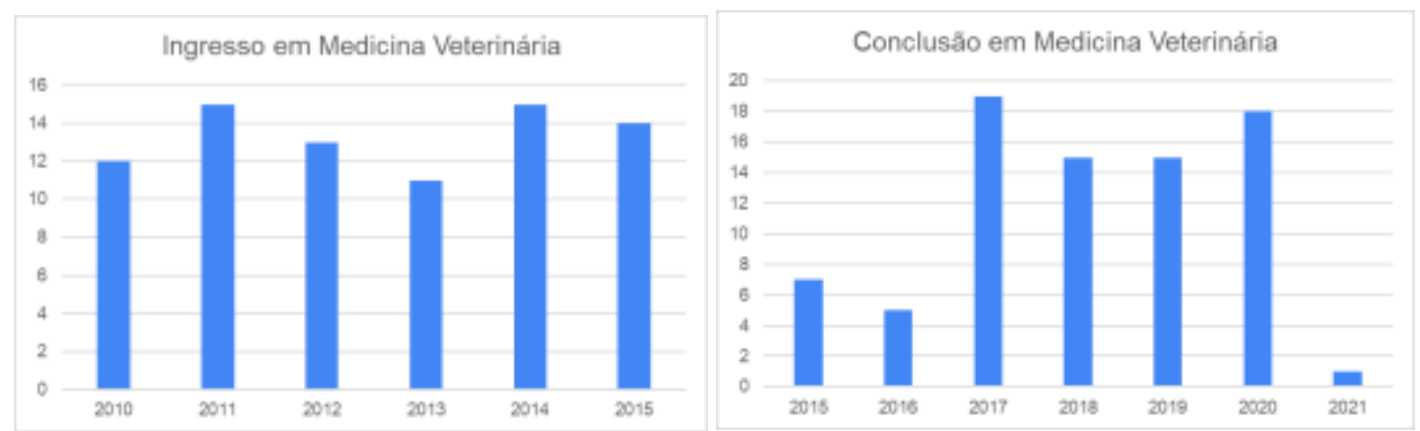

Fonte: Elaborada pelos autores (Mai/2021).

O acesso ao ambiente novo da universidade impacta na vida dos estudantes, muito além da questão econômica, introduz os alunos num ambiente de muitos conhecimentos, causa mudanças no cotidiano, além de proporcionar uma sensação de orgulho por um status superior. Às vezes, sendo o primeiro membro da família a ingressar no ensino superior (Barbosa, 2019).

\subsection{Trajetória Acadêmica}

Dos participantes desta pesquisa, $62,25 \%$ reprovaram em algum componente curricular. A média ponderada foi de 
3,2 reprovações e a mediana de 2 reprovações, o que equivale a permanência de no mínimo mais um ano e meio na universidade. Vasconcelos e Silva (2011) definem o conceito de retenção para o ensino superior como a permanência prolongada do aluno na universidade, permanecendo na condição de matriculado no curso inicial por um tempo maior que o instituído pelo currículo institucional. Ainda, o termo retenção refere-se como repetência no contexto no qual o aluno no ano subsequente cursa a mesma etapa do ano anterior, o que gera uma inconstância ou retardo quanto à trajetória regular esperada (Brasil, 2016).

O tema tem-se constituído relevante na maioria dos países, demonstrando que o abandono e as sucessivas reprovações são fenômenos complexos e multidimensionais que constituem uma problemática educativa e social (Vidales, 2009). É importante ressaltar que os termos retenção e a evasão estão relacionados, pois o atraso na conclusão da graduação pode suceder na evasão (Silva et al., 2006). Além de um investimento público que deixa de gerar benefícios não havendo o devido retorno, no caso das instituições públicas de ensino superior, gera prejuízo para cada estudante que abandona, reprova ou necessita de mais tempo do que o indicado para conclusão de seu curso, já que este acaba por deixar de receber os benefícios proporcionados pela diplomação e consequentes rendimentos como graduado (Saliba et al., 2006).

Cerca de 33\% dos alunos que ingressam em um programa de bacharelado no Brasil se formam na duração teórica do programa, que geralmente tende a ser de 4 ou 5 anos dependendo do programa, abaixo da média de 39\% (segundo países com dados disponíveis na Organização para Cooperação e Desenvolvimento Econômico - OCDE). Ainda, a taxa de conclusão aumenta para 50\% após três anos adicionais, ainda abaixo da média de 67\%. Dos alunos restantes que não se formaram dentro deste prazo, cerca de um terço ainda estão matriculados no ensino superior e dois terços deixaram o sistema sem se formar (OCDE, 2019).

Os alunos de nível superior são colocados frente a desafios durante todo o período que compreende a graduação, alguns com maiores ou menores intensidade, dependentes da percepção de cada indivíduo (Barros, 2015). Dentre as principais dificuldades enfrentadas durante a graduação, os participantes destacaram: problemas com o professor (didática, cobrança e falta de sensibilidade são a maioria dos relatos), distância da família, questões psicológicas e dificuldades de aprendizagem (sendo os quatro itens mais citados, que representam $56,7 \%$ das queixas). Outros apontamentos citados podem ser observados na Figura 2.

Figura 2 - Resultado em números absolutos de todas as dificuldades citadas pelos egressos participantes durante a graduação em medicina veterinária na UFFS.

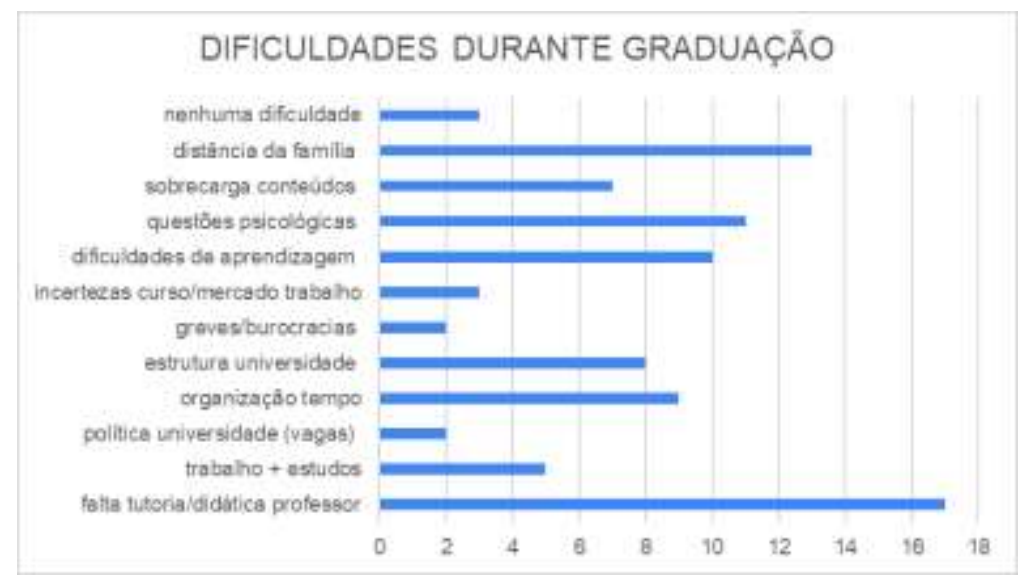

Fonte: Elaborada pelos autores (Mai/2021).

O período que compreende a transição do aluno do ensino médio para a universidade teoricamente não deveria gerar danos. É considerado um momento repleto de possibilidades, porém, sabe-se que quanto maior o nível de expectativas, maiores são as consequências criadas por estas (Gomes \& Soares, 2013). Alunos focados no desempenho acadêmico, mais seguros da 
escolha do curso, com percepções e tendências realistas tendem apresentar melhor adaptação e rendimento na aprendizagem, comparado a alunos que possuem indecisões relacionadas ao curso e que acabam por criar expectativas mais distantes do seu potencial, dificultando a adaptação ao novo meio social (Fernandes \& Almeida, 2005).

As novas exigências de estudo que caracteriza a rotina universitária, marcada pela grande quantidade de conteúdos em diferentes disciplinas, também pode ser citada como fator determinante para o desempenho do estudante nas variadas temáticas, levando inclusive à reprovação e consequente retenção no curso (Lamers et al., 2017).

O apoio institucional compatível à adaptação, ao rendimento e a atenção à atuação do aluno no ambiente acadêmico podem ser fatores associados ao desempenho, que também dependerá de suas características psicológicas. Em pesquisa sobre o processo de adaptação ao ensino superior e o rendimento acadêmico dos ingressantes, verificou-se que a universidade que propicia um espaço receptivo com integração entre recursos pessoais e institucionais pode auxiliar no desenvolvimento e utilização dos potenciais pessoais dos alunos recém-chegados, além de interferir na sua percepção de bem-estar físico e psicológico (Cunha \& Carrilho, 2005).

Dificuldades que correspondem a algumas das citadas pelos participantes da pesquisa, no que diz respeito a novas rotinas, organização do tempo, dificuldades de aprendizagem e sobrecarga de conteúdo.

Para Cavalcanti et al. (2010), as dificuldades quanto à didática e deficientes métodos de ensino empregados por docentes nas aulas foram fatores relevantes no desempenho de estudantes do curso de odontologia na Universidade Estadual da Paraíba, sendo a insatisfação com o corpo docente do curso uma das causas da evasão. Para tanto, é fundamental que a IES (Instituição de Ensino Superior) invista em uma educação permanente de seus docentes e estimule suas habilidades pedagógicas e investigativas para vincular de maneira mais efetiva os estudantes a seus processos de aprendizagem (Faúndez et al., 2012).

As expectativas dos alunos durante a graduação podem impactar positivamente ou negativamente seu rendimento, bem-estar e escolhas, e a reprovação é um desses aspectos desfavoráveis (Diogo et al., 2016). Quando questionados se cursar a mesma disciplina novamente fez diferença, $49 \%$ das respostas foram positivas, $18,9 \%$ negativas, $18,9 \%$ parciais e 13,2\% não souberam responder. Os períodos da graduação em que ocorreram as reprovações com maior frequência podem ser observados na Figura 3.

Figura 3 - Períodos do curso em que ocorreram as reprovações durante a graduação em medicina veterinária na UFFS.

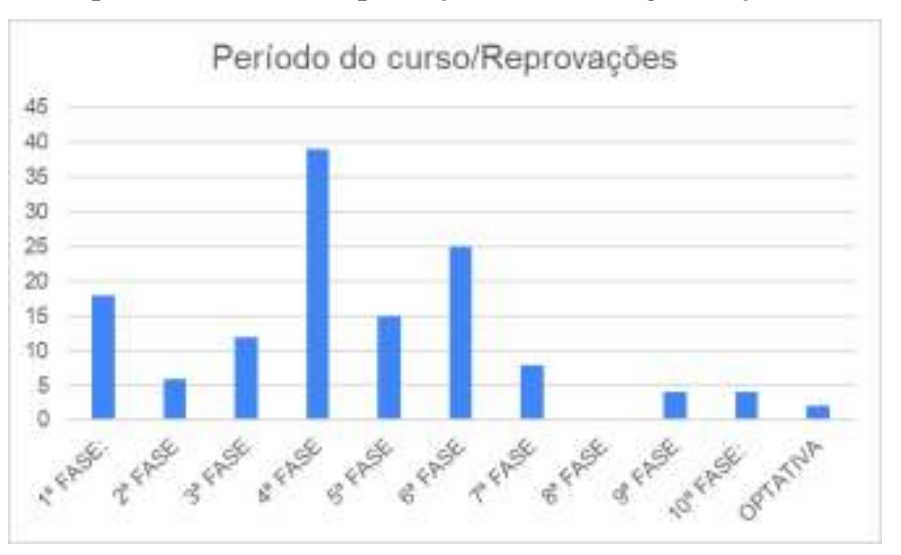

Fonte: Elaborada pelos autores (Mai/2021).

Observa-se que as reprovações foram maiores na metade do curso, correspondendo a transição dos componentes curriculares básicos para os específicos. Um processo de adaptação bem-sucedido, especialmente no primeiro ano, reflete como preditor importante da persistência e do sucesso dos alunos ao longo das suas experiências acadêmicas, bem como determina padrões de desenvolvimento estabelecidos pelos alunos ao longo de sua vida universitária (Cunha \& Carrilho, 2005). Segundo 
Drake et al. (2014), alunos do segundo e terceiro ano apresentam níveis de ansiedade e depressão mais altos comparados aos alunos dos demais anos da graduação, o que pode colaborar nas reprovações observadas no presente estudo.

Sobre a percepção de docentes e coordenadores de curso de ensino superior, um dos fatores condicionantes para o desempenho acadêmico, mas não único, é quando o ensino básico não possibilita a base necessária para a continuidade dos estudos no ensino superior, podendo refletir em evasão (Veloso \& Almeida, 2002; Vargas \& Paula, 2013).

Outra questão destacada pelos estudantes que passaram por reprovação no curso de odontologia foi quanto a expectativa de vivências em atividades curriculares práticas relacionadas com a profissão, desde o início do curso levando o estudante a um distanciamento do curso (Lamers et al., 2017). É importante que o curso propicie vivências aos estudantes, logo no início do curso superior, a percepção exata sobre a profissão e o contato com todos os domínios da medicina veterinária. Uma abordagem falha pode afetar o desempenho durante o curso, conforme reforçam Cunha e Carrilho (2005), revalidando as afirmações semelhantes aos participantes da presente pesquisa.

Conhecimentos práticos e possibilidades de desenvolver habilidades na futura profissão são aspectos importantes que os estágios extracurriculares podem proporcionar aos estudantes, no entanto, mesmo não sendo obrigatório, devem ser equivalentes com a área de formação e dar oportunidade de colocar a teoria na prática (Martins, 2012). Durante a graduação 87,5\% dos participantes aproveitaram para realizar estágios extracurriculares (dos 54 que responderam, 9,3\% fizeram no início; 42,6\% na metade; $14,8 \%$ no final; e 33,3\% durante toda a graduação) e 86,3\% cursos extracurriculares.

Estágios extracurriculares permitem ampliar a rede de contatos e abrem portas para oportunidades, envolve o contato com a prática e a preparação para a trajetória profissional. Acredita-se que a realização destes se dê de forma mais proveitosa da metade para o final da graduação, momento em o graduando já possui conhecimento suficiente para entender as demandas e necessidades da profissão (Santos et al., 2017).

Os participantes também citaram a importância da realização de cursos extracurriculares no encorajamento e possibilidade de praticar os conhecimentos teóricos aprendidos na graduação. Além da participação em semanas acadêmicas e palestras oferecidas dentro ou fora da universidade.

Na Figura 4 podem ser observadas as áreas de interesse da medicina veterinária dos participantes ao ingressarem, sendo que $48,8 \%$ mudaram de opinião durante a trajetória acadêmica.

Figura 4 - Áreas da medicina veterinária e as mudanças de escolha durante a graduação dos participantes da pesquisa.

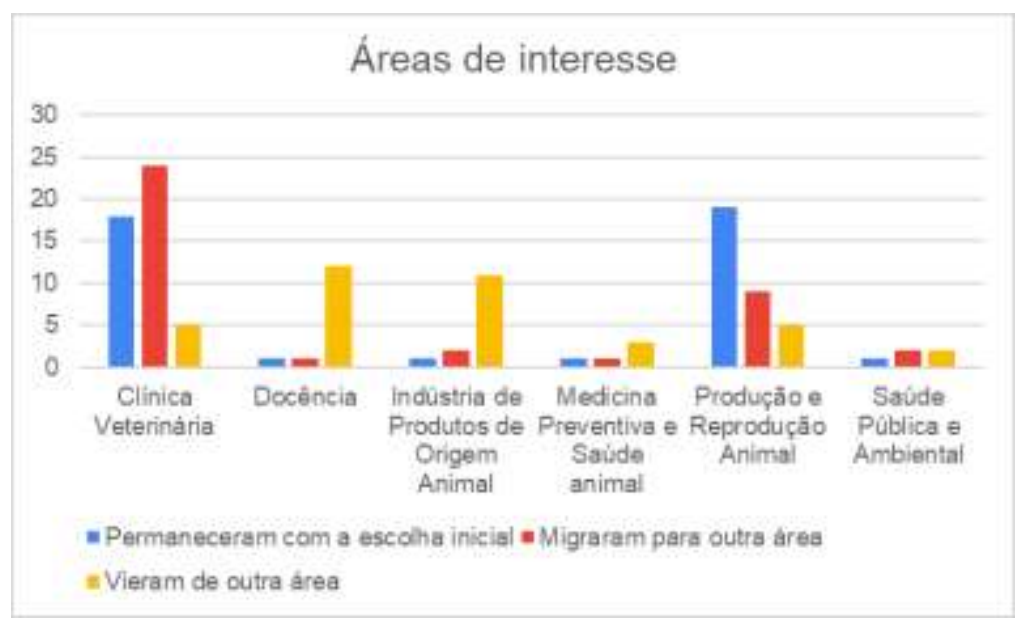

Fonte: Elaborada pelos autores (Mai/2021).

As mudanças de área foram motivadas principalmente por oportunidades de conhecer outras especialidades durante a graduação e depois de formado, por afinidade, disponibilidades do mercado de trabalho e realidade pós-formação (79\% das 
respostas). A maioria dos acadêmicos ingressou no curso com interesse na área clínica. A popularidade de áreas da veterinária que relacionam diagnósticos e tratamento de doenças em animais predominantemente curativas cresceram tanto a ponto de virar uma unanimidade no conhecimento social sobre o médico veterinário (Nogueira, 2018).

Por sua vez, o próprio currículo e a influência de grupos de pensamento predominante dentro da instituição procedem de modo a fortalecer essa tendência, porém as IES têm o dever de mostrar todas as atribuições deste profissional no começo da graduação, sendo esta uma importante ferramenta para que os alunos tomem conhecimento sobre o assunto e toda sua dimensão (Pfuetzenreiter \& Zylbersztajn, 2008).

No entanto, acredita-se que o reconhecimento da importância da profissão para a sociedade está diretamente relacionada à dependência de sua relevância social. As questões mais apontadas para este século, que mais fazem parte dessa relevância estão relacionadas à sustentabilidade: a produção de alimentos com utilização de métodos sustentáveis considerando o crescimento populacional, a proteção do meio ambiente à degradação e perda da biodiversidade, e a profilaxia das novas zoonoses com potencial epidêmico (Nielsen, 1997). O problema é que no contexto regional que muitas vezes as IES se inserem, acabam por habilitar os estudantes para as oportunidades locais, direcionando e/ou influenciando-os na sua perspectiva de atuação, limitandoos profissionalmente (Rolim \& Serra, 2015).

Quando perguntados sobre as atividades que os alunos tiveram oportunidade de desenvolver durante o período de graduação, os projetos de extensão foram os mais citados, seguidos por participação em eventos nacionais (82,5\%), projetos de pesquisa (76,3\%), apresentação individual em eventos com 71,3\% e organização de eventos com 63,7\%. Outros aspectos podem ser observados na Figura 5.

Figura 5 - Atividades extracurriculares realizadas durante a graduação em medicina veterinária na UFFS dos egressos participantes da pesquisa.

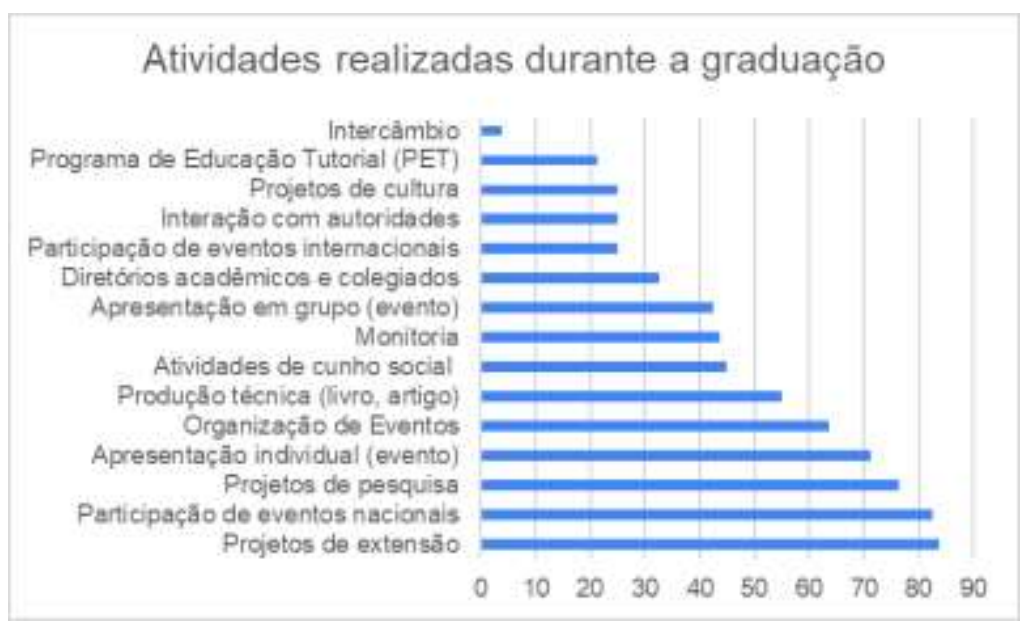

Fonte: Elaborada pelos autores (Mai/2021).

Os estudantes reconhecem a importância da participação em projetos de iniciação científica, extensão e monitorias, e de como essas experiências colaboram com o crescimento pessoal e intelectual, seguido por um número bem expressivo de citações quanto a participação ao Programa de Educação Tutorial - PET, o que os proporcionou contato direto com os produtores, prática da extensão rural, comunicação técnica e crescimento pessoal confrontando com os comentários de que quem não realizou essas práticas e que fariam diferente numa oportunidade.

A extensão possibilita práticas diversas com a comunidade, gerando integração, oferecendo conhecimento para o desenvolvimento da sociedade e permitindo novas experiências, baseadas na interação de pessoas de classes sociais muitas vezes distintas (Mauerberg Junior et al., 2014). Ainda, os projetos de extensão na universidade propõem muito mais do que colaborar 
com as demandas sociais, eles tendem a integração das atividades de pesquisa e ensino com essas demandas, reafirmando o compromisso social da universidade com a promoção e garantia dos valores democráticos, de igualdade e desenvolvimento social (Silva et al., 2014).

\subsection{Trajetória Profissional}

O processo complexo de transição entre o ambiente universitário e a posição enquanto graduando para a entrada no mercado de trabalho e o papel profissional exige uma imensa mobilização frente a adaptação, inclusive, pode muitas vezes colocar à prova as capacidades pessoais, interferindo diretamente na busca pelo primeiro emprego (Magalhães \& Teixeira, 2013).

Dentre as principais dificuldades apontadas na vida profissional, os participantes destacaram: insegurança, falta de conhecimento técnico e/ou prático, adaptação a rotina, lidar com pessoas, questões financeiras/desvalorização, hierarquia/respeito e falta de experiência (71,6\% das respostas).

Quando questionados se a graduação proporcionou vivências práticas e satisfatórias na área de escolha do estágio obrigatório, 51,25\% responderam que sim (destacando principalmente docentes com domínio na área, teoria e/ou prática consolidadas e a participação em projetos e monitorias), 27,5\% não (devido a falta de estrutura e carência de aulas práticas ou rotina) e $21,25 \%$ parcialmente.

Espera-se que o estágio obrigatório seja uma etapa positiva propiciando conhecimento e práticas específicas da profissão, contribuindo para o desenvolvimento do discente, além da possibilidade de formar profissionais diferenciados conforme necessidades do mercado de trabalho (UFFS, 2015). Ainda, é um momento em que os alunos entendem os mecanismos e as políticas do mercado de trabalho, bem como a aplicabilidade do conhecimento recebido durante a graduação (Polzin, 2019).

Dos 80 participantes, 19,2\% declararam que foram efetivados nos mesmos locais onde fizeram o estágio, principalmente aqueles que optaram por agroindústrias produtoras de alimentos de origem animal, demonstrando a demanda deste mercado. E $8 \%$ daqueles que fizeram o estágio obrigatório em universidades ingressaram diretamente em programas de residência ou mestrado.

A demanda por posteriores especializações após formação, tanto em mestrados e doutorados, pós-graduação e residências indica a busca pelo reconhecimento e destaque na área de escolha, bem como a realização de concursos públicos para garantia de segurança e estabilidade financeira.

Quando perguntados sobre as escolhas que os participantes fariam diferente na graduação, as mais citadas e que representam 68,9\% das respostas foram: participar de mais projetos de extensão, grupos de estudos, monitorias; estudar mais; estar aberto às outras áreas; fazer mais estágios; ou não fariam nada diferente. As menos citadas e que representam 23,3\% das respostas foram: ter feito iniciação científica; ter feito rede de contatos com profissionais, colegas e professores; participar de eventos; ser proativo. O restante das respostas foi quanto a se divertir mais e cuidados da saúde mental, ou não responderam.

Em tempos de transformações velozes e intensas relacionadas a novas tecnologias e consequentemente ao mercado de trabalho, a capacitação pessoal e profissional se faz necessário (Chiavenato, 2014). O mercado de trabalho exige do profissional muito mais que as habilidades técnicas aprendidas na graduação, demandam pró-atividade e participação da rotina da empresa, tanto solucionando problemas quanto percebendo oportunidades. As chamadas soft skills ou people skills são as habilidades pessoais capazes de agregar valor tanto para quem expressa a competência quanto para a sociedade, logo para o mercado de trabalho (Barro, 2021).

Quando perguntados quais habilidades não aprenderam ou desenvolveram na graduação e que enfrentaram dificuldades na rotina de trabalho, 37,5\% responderam que situações de cargos e posições de liderança, seguido da falta de criação de uma rede de contatos influentes e permanentes com colegas da área (35\%), dificuldade de manter equilíbrio emocional frente a situações inesperadas (30\%), dificuldade de dar e receber feedback $(28,7 \%)$ e a criatividade $(27,5 \%)$. Outros aspectos 
podem ser observados na Figura 6.

Figura 6 - Habilidades pessoais questionadas aos participantes da pesquisa se foram desenvolvidas durante a graduação em medicina veterinária.

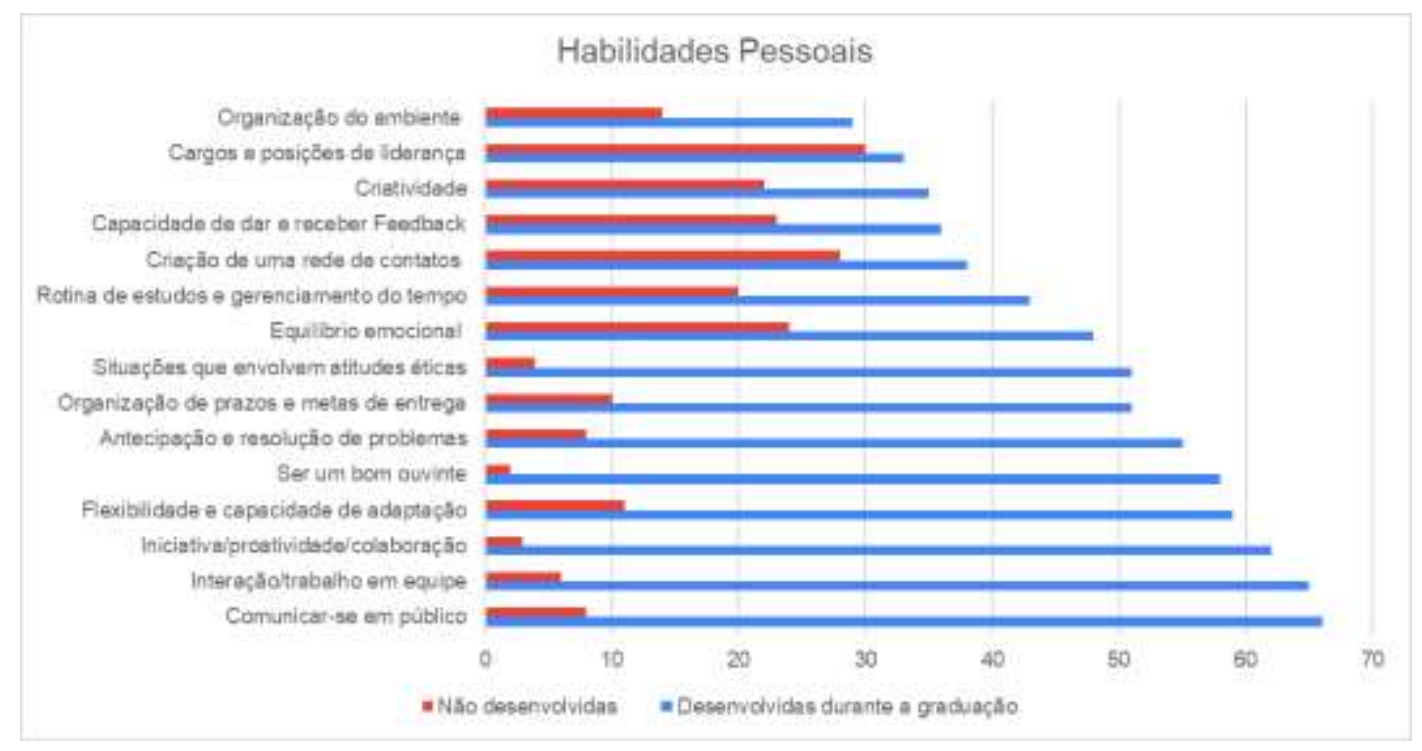

Fonte: Elaborada pelos autores (Mai/2021).

Considerando que o conhecimento técnico vai ser aprendido e todos os graduados terão a mesma base, o diferencial na contratação destes futuros profissionais serão as habilidades desenvolvidas (Penhaki, 2019).

Com o propósito de nortear a formação de líderes, capazes de trabalhar em grupo, inovar, criar e lidar com situações de estresse, o CFMV juntamente com a OIE organizaram o documento: "Estratégias de ensino-aprendizagem para desenvolvimento das competências humanísticas propostas para formar médicos veterinários para um mundo melhor" e servem como um elemento norteador desde 2010 para as Diretrizes Curriculares dos cursos de graduação. Além do desenvolvimento dessas habilidades, o documento propõe técnicas e ferramentas de ensino capazes de auxiliar docentes e IES a atingirem patamares mais elevados de excelência no ensino e na formação de médicos veterinários (CFMV, 2012).

O que se sugere são novas estratégias e novas formas de apresentar o conteúdo de forma a desenvolver as competências humanísticas para formar pessoas mais tolerantes, mais humanas e com excelente capacidade técnica, que vão se diferenciar no mercado competitivo, pois não basta o profissional apenas estar preparado, mas apto às mudanças e, portanto, adaptável (Castilho, 2015).

As respostas para as habilidades desenvolvidas durante a graduação e que fez diferença na sua rotina de trabalho foram: $82,5 \%$ citaram comunicar-se em público; $81,3 \%$ o trabalho em equipe; $77,5 \%$ citaram a iniciativa, proatividade e colaboração; $73,8 \%$ a flexibilidade e a capacidade de adaptações frente a mudanças; $72,5 \%$ ser um bom ouvinte; e $68,8 \%$ a antecipação e a resolução de problemas. Estas atitudes são compatíveis com as competências humanísticas apresentadas por Tavolaro (2016) que correspondem à capacidade de lidar com as inúmeras variáveis, desde inteligência emocional, às questões humanas de relacionamento, de compreensão da realidade sob um olhar amplo, de comunicação, liderança, organização e gestão, incluindo-se aí a gestão de si mesmo.

Quando perguntados sobre componentes curriculares importantes que são necessários para enfrentar os desafios do mercado de trabalho, os participantes citaram: empreendedorismo, administração de empresas, gestão de pessoas, vendas e marketing em todas as áreas da medicina veterinária, seguida de disciplinas que abordem a preparação para entrevistas de emprego, de processos seletivos em residências e mestrado como psicologia, com ênfase em desenvolvimento interpessoal e 
pessoal.

O déficit de aprendizado ou a falta de experiência nas áreas sugeridas podem indicar as habilidades que lhe são exigidas ou colocadas à prova na rotina de trabalho, porém para Gondim (2002), a inconstância no mercado não permitiria o andar incorporado a uma estrutura curricular, para que um perfil tão vasto e diverso fosse atendido, ocasionando entre algumas consequências, o prolongamento do tempo de duração de um curso superior, contudo, é claro o desejo dos estudantes que a formação científica e a formação técnico-profissional caminhem juntas.

Mudanças constantes a curto, médio e longo prazo no ensino da medicina veterinária são essenciais na busca pela excelência na educação superior. O desejável seria que os docentes universitários dominassem tanto a técnica quanto tivessem a sensibilidade de levar em conta a necessidade de cada discente (Cobucci, 2017). Para superar os espaços que o processo de ensino-aprendizagem para adultos no ensino superior demonstra, os docentes devem ter a oportunidade de formação e acompanhamento constante e transição dos métodos inovadores, além de apoio motivacional e reconhecimento das instituições de ensino e da sociedade (Torres \& Chirelli, 2019).

\section{Conclusão}

Mais da metade dos egressos tiveram reprovações durante o curso, o que aumentou o tempo de permanência na universidade, prolongando a formação a um período médio de um ano e meio a mais. As reprovações mais frequentes ocorreram nos períodos das grandes transformações, tanto pedagógicos quanto psicossociais, que correspondem a transição dos conteúdos básicos para os específicos, mas cursar a mesma disciplina fez diferença no aprendizado para a maioria deles.

Contudo, ainda no contexto universitário, para alguns com maior ou menor intensidade, a dificuldade de aprendizagem das metodologias aplicadas no ensino superior, somada à didática docente, a distância da família e questões psicológicas foram os fatores influenciadores no desempenho acadêmico.

Os egressos demonstraram participação e interesse por experiências pedagógicas tanto dentro da universidade quanto fora colocando em prática as teorias e explorando as possibilidades da profissão, o que proporcionou desenvolver e aprimorar habilidades humanísticas, e que são tão importantes frente aos desafios que a realidade pós formação e o mercado de trabalho exigem, atenuando ou ainda facilitando o processo de transição, repleto de inseguranças e falta de experiências.

No transcorrer da graduação ocorreu a mudança da escolha pela área de atuação para muitos participantes. Quase metade dos acadêmicos que ingressam com a visão clínica da profissão mudaram o interesse para inspeção de produtos de origem animal, docência, reprodução e produção animal, seja por oportunidade de conhecer novas áreas ou pela oferta de emprego, muitas vezes sendo efetivados imediatamente após a conclusão do estágio curricular obrigatório.

Há relatos de ex-alunos que se pudessem fazer diferente trabalhariam mais as habilidades interpessoais, sendo mais proativos, participariam mais de projetos de pesquisa, extensão, grupos de estudos e que criariam uma rede de contatos profissionais influentes. Esses aspectos correspondem em partes às dificuldades citadas pelos alunos de não ter aprendido ou desenvolvido durante a graduação, fundamentando ainda, o não saber agir em situações de liderança, o equilíbrio emocional e a criatividade, que dificultaram a prática na rotina do trabalho.

Para tanto, os egressos apontaram algumas sugestões de componentes curriculares que contemplariam conhecimentos requeridos na rotina e que poderiam fazer a diferença, como gestão de pessoas e empreendedorismo, vendas e marketing pessoal e comercial, psicologia e preparação para entrevistas de emprego ou programas de residência.

Assim há a necessidade de um olhar mais amplo por parte das universidades para oportunizar o reconhecimento docente pela importância da introdução e suporte didático-pedagógico contemporâneo e efetivo, que se convertam em uma formação de profissionais críticos, resilientes, otimistas, colaborativos, criativos, organizados, com uma comunicação eficiente, que saibam ouvir e planejar, necessário à exigência do mercado de trabalho e à sociedade. 
Os possíveis estudos para ampliar o entendimento do processo de formação e desenvolvimento das habilidades pessoais no meio acadêmico seria a avaliação do ingresso ao mercado de trabalho: tempo até obter o primeiro emprego, dificuldades, salário, etc. Ainda, este estudo poderia ser aplicado a todos os acadêmicos durante e após finalizarem a graduação, a fim de identificar os interesses iniciais e perspectivas do curso.

\section{Referências}

Barbosa, M. L. O. (2019). Democratização ou massificação do Ensino Superior no Brasil? | Higher Education in Brazil: democratization or massification? Revista de Educação PUC- Campinas, 24(2), 240-253. https://doi.org/10.24220/2318-0870v24n2a4324

Barro, D. (2021). Competências transversais na formação integral de egressos do curso de Pedagogia em uma instituição de educação superior. [Tese de Doutoramento, Universidade La Salle]. Repositório Unilasalle https://repositorio.unilasalle.edu.br/handle/11690/1763

Barros, A.S.X. (2015). Expansão da Educação Superior no Brasil: limites e possibilidades. Educ.Soc., 36(131), 361-390. https://doi.org/10.1590/ES01017330201596208

Brasil. (2016). Instituto Nacional de Estudos e Pesquisas Educacionais Anísio Teixeira (Inep). Censo da Educação Superior 2010-2014. Brasília, DF.

Resolução no 3, de 15 de agosto de 2019. (2019). Institui Diretrizes Curriculares Nacionais dos Cursos de Graduação em Medicina Veterinária e dá outras providências. Brasília, DF. https://www.in.gov.br/web/dou/-/resolucao-n-3-de-15-de-agosto-de-2019-210946881

Castilho, M. L. R. (2015). Competências humanísticas no curso de Medicina Veterinária: Relato de experiência multidisciplinar. Revista Unimar Ciências, 24, (1-2). https://educere.bruc.com.br/arquivo/pdf2017/25590_13312.pdf

Cavalcanti, A. L., Lima W. G., Marques. J. L., Alves, H. F. C. \& Granville-Garcia, A. F. (2010). Motivos de ingresso e de evasão dos acadêmicos de odontologia de uma instituição pública. Rev. Odontol UNESP, 39(2), 95-99. https://www.revodontolunesp.com.br/article/588018ad7f8c9d0a098b4d72/pdf/rou-39-2-95.pdf

Chiavenato, I. (2014). Gestão de pessoas: o novo papel dos recursos humanos nas organizações. Manole.

Cobucci, G. C. (2017). Metodologias ativas e aspectos pedagógicos no ensino de graduação em Medicina Veterinária. [Dissertação Mestrado na Universidade Federal de Viçosa]. Repositório UFV https://www.locus.ufv.br/bitstream/123456789/17771/1/texto\%20completo.pdf

Conselho Federal de Medicina Veterinária [CFMV]. (2020). Balanço do triênio 2017-2020. Censo Transparência. Brasília, DF.

Conselho Federal de Medicina Veterinária [CFMV]. (2012). Estratégias de ensino aprendizagem para desenvolvimento de competências humanísticas: Propostas para formar médicos veterinários para um mundo melhor. Brasília, DF.

Cunha, S. M. \& Carrilho, D. M. (2005). O processo de adaptação ao ensino superior e o rendimento acadêmico. Psicologia Escolar e Educacional, 9(2), 215224. https://doi.org/10.1590/S1413-85572005000200004

Diogo, M. F., Raymundo, L. S., Wilhelm, F. A, X., Andrade, S. P. C., Lorenzo, F. M., Rost, F. T. \& Bardagi, M. P. (2016). Percepções de coordenadores de curso superior sobre evasão, reprovações e estratégias preventivas. Avaliação: Revista da Avaliação da Educação Superior (Campinas), 21(1), 125-151. https://doi.org/10.1590/S1414-40772016000100007

Drake, A., Hafen JR, M. \& Rush, B. R. (2014). Promoting well-being among veterinary medical students: protocol and preliminary findings. Journal of veterinary medical education, 41(3), 294-300. DOI: 10.3138/jvme.0214-026R

Faúndez, F., Muñoz, K. \& Cornejo, F. (2012). Percepción sobre el modelo educativo basado en competencias y su contribución a la retención de estudiantes de la universidad de Talca. In:Conferencia Latinoamericana Sobre el Abandono en la Educación Superior (pp. 738-744).

Fernandes, E. P. \& Almeida, L. S. (2005). Expectativas e vivências acadêmicas: Impacto no rendimento dos alunos do $1^{\circ}$ ano. Psychologia, 40(1), 267-278. Repositório http://hdl.handle.net/1822/8873

Gomes, G. \& Soares, A. B. (2013). Inteligência, habilidades sociais e expectativas acadêmicas no desempenho de estudantes universitários. Psicologia: Reflexão e Crítica, 26(4), 780-789. https://doi.org/10.1590/S0102-79722013000400019

Gondim, S. M. G. (2002). Perfil profissional e mercado de trabalho: relação com formação acadêmica pela perspectiva de estudantes universitários. Estudos de Psicologia (Natal), 7(2), 299-309. https://doi.org/10.1590/S1413-294X2002000200011

Lamers, J. M. S., Santos, B. S. \& Toassi, R. F. C. (2017) Retenção e evasão no ensino superior público: estudo de caso em um curso noturno de odontologia. Educação em Revista, 33, 01-26. https://doi.org/10.1590/0102-4698154730

Magalhães, M. O. \& Teixeira, M. A. P. (2013). Antecedentes de comportamentos de busca de emprego na transição da universidade para o mercado de trabalho. Psicologia: Teoria e Pesquisa, 29(4), 411-419. https://doi.org/10.1590/S0102-37722013000400007

Martins, S. P. (2012). Estágio e relação de emprego. Atlas.

Mauerberg Junior, A., Guerreiro, J., Costa, C. C. M. \& Ferreira, M. A. M. (2014). A universidade como espaço territorial de inovação: o papel da extensão universitária no incentivo às práticas inovadoras de gestão. Organizações Rurais \& Agroindustriais, 16(2), 220-232. http://repositorio.ufla.br/jspui/handle/1/8820

Nielsen, N. O. (1997). Reshaping the veterinary medical profession for the next century. Journal of American Veterinary Medical Association, 210(9), 12721274. 
Nogueira, C. S. L. (2018). A importância da inclusão do médico veterinário nos núcleos de apoio à saúde da família - NASF. [Dissertação Mestrado na Universidade Estadual Paulista - UNESP]. Repositório UNESP http://hdl.handle.net/11449/153088

Organização Mundial da Saúde Animal [OIE] (2012). Recomendaciones de la OIE sobre las competencias mínimas que se esperan de los veterinários recién licenciados para garantizar servicios veterinários nacionales de alta calidad: França. https://rr-americas.oie.int/wp-content/uploads/2020/01/dayone-b-esp-vc.pdf

Organização para Cooperação e Desenvolvimento Econômico [OCDE] (2019). Education at a Glance: OCDE - Indicators. https://www.oecd.org/latinamerica/paises/brasil-portugues/

Penhaki, J. D. R. (2019). Soft skills na indústria 4.0. [Dissertação Mestrado em Tecnologia e Sociedade na Universidade Tecnológica Federal do Paraná UTFPR]. Repositório UTFPR http://repositorio.utfpr.edu.br/jspui/handle/1/4275

Pereira A.S. et al. (2018). Metodologia da pesquisa científica. UFSM. https://repositorio.ufsm.br/bitstream/handle/1/15824/Lic_Computacao_MetodologiaPesquisa-Cientifica.pdf?sequence $=1$

Pfuetzenreiter, M. R. \& Zylberstajn, A. (2008). Percepções de estudantes de medicina veterinária sobre a atuação na área da saúde: um estudo baseado na idéia de "estilo de pensamento" de Ludwik Fleck. Ciência \& Saúde Coletiva, 13, 2105-2114. https://doi.org/10.1590/S1413-81232008000900015

Polzin, F. R. (2019). O estágio obrigatório como instrumentos de inserção no mercado de trabalho. [Dissertação Mestrado da Universidade Tecnológica Federal do Paraná - UTFPR]. Repositório UTFPR http://repositorio.utfpr.edu.br/jspui/handle/1/4002

Rolim, C. \& Serra, M. (2015). Ensino superior e desenvolvimento regional: avaliação do impacto econômico de longo-prazo. Revista Brasileira de Estudos Regionais e Urbanos, 3(1), 85-106. https://www.revistaaber.org.br/rberu/article/view/29

Saliba N. A, Moimaz, S. A. S, Raphael, H. S, Pagliari, A. V. \& Rodrigues, R. P. C. B. (2006). Organização curricular, evasão e repetência no curso de odontologia: um estudo longitudinal. Rev. Odontol. UNESP, 35(3), 209-214. https://www.revodontolunesp.com.br/article/588017de7f8c9d0a098b494e

Santos, S. Y, Oliveira, A. G. L. \& Costa, A. M. (2017). O estágio na formação profissional. Comunicação apresentada em XVII Colóquio Internacional de Gestão Universitária. Repositório UFSC https://repositorio.ufsc.br/xmlui/handle/123456789/181144

Sherman, D.M. (2010). A Global Veterinary Medical Perspective on the Concept of One Health: Focus on Livestock. ILAR Journal, 51(3), 281-87. DOI: 10.1093/ilar.51.3.281.

Silva, R. R. C. M., Mainier, F. B. \& Passos, F. B. (2006). A contribuição da disciplina de introdução à engenharia química no diagnóstico da evasão. Ensaio: Avaliação e Políticas Públicas em Educação, 14(51), 261-277. https://doi.org/10.1590/S0104-40362006000200008

Silva, F. M., Melo, P. A., Silva, J. E. O. \& Ramos, A. M. (2014). Compromisso Social e Extensão: A Prática da Universidade Federal de Santa Catarina. Revista Alcance, 21(1), 77-97. https://doi.org/10.14210/alcance.v21n1.p077-097

Tavolaro, P. (2016). A necessidade do fortalecimento do conhecimento humanístico na formação do médico-veterinário: a visão de estudantes do segundo semestre de graduação. Revista de Educação Continuada em Medicina Veterinária e Zootecnia do CRMV-SP, 14(1), 28-34. https://doi.org/10.36440/recmvz.v14i1.31034

Torres, V. F. \& Chirelli, M. Q. (2019). Formação Docente na Medicina Veterinária: desafios e estratégias desvendados pela análise temática. CIAIQ2019, 1, 681-690. https://proceedings.ciaiq.org/index.php/CIAIQ2019/article/view/2238

Universidade Federal da Fronteira Sul (2015). Regulamento de Estágio da UFFS - Resolução nº 07/2015. Chapecó: SC

Universidade Federal da Fronteira Sul (2010). Projeto pedagógico do curso de graduação em medicina veterinária: bacharelado. Chapecó: SC. https://www.uffs.edu.br/atos-normativos/ppc/ccmvre/2010-0001

Vargas, H. M. \& Paula, M. F. C. (2013). A inclusão do estudante-trabalhador e do trabalhador estudante na educação superior: desafio público a ser enfrentado. Avaliação: Revista Da Avaliação Da Educação Superior, 18(2), 459-485. http://periodicos.uniso.br/ojs/index.php/avaliacao/article/view/1590

Vasconcelos, A. L. F. S. \& Silva, M. N. Uma investigação sobre os fatores contribuintes na retenção dos alunos no curso de Ciências Contábeis em uma IFES: um desafio à gestão universitária. In: Anais dos Colóquios Internacionais Sobre Gestão Universitária, Florianópolis, SC.

Veloso, T. C. M. A. \& Almeida, E. P. (2002). Evasão nos cursos de graduação na Universidade Federal de Mato Grosso, campus universitário de Cuiabá - um processo de exclusão. Série-Estudos - Periódico Do Programa De Pós-Graduação Em Educação Da UCDB, (13), 133-148. https://www.serieestudos.ucdb.br/serie-estudos/article/view/564

Vidales, S. (2009). El fracaso escolar en la educación media superior. El caso del bachillerato de una universidad mexicana. Rev. Iberoamericana calidad, eficacia cambio educ., 7(4), 321-341. https://revistas.uam.es/reice/article/view/5395 